\title{
Effect of Cyclic Load on California Bearing Ratio of Soaked Clay
}

\author{
Robert Nini \\ University of Balamand \\ Balamand, El Koura, Lebanon \\ robert.nini@balamand.edu.lb
}

\begin{abstract}
The quality of pavement is affected mostly by the type of subgrade soil and in many countries the subgrade soil is weak. One way to measure the strength of the subgrade soil is the California Bearing Ratio test which is a penetration test under continuous uniform loading. But the real traffic surcharge on roads is simulated to be more cyclic load than uniform load. Our objective is to perform the CBR test on different clayey soil samples under cyclic load. This will be done by loading the soil sample to a penetration of 0.in. then to stop the loading for a while. After it, the CBR plunger will penetrate again the soil. This cycle of loading - unloading reloading will be repeated two times in order to study the effect of the cyclic load on the CBR values. After this, the same procedure will be repeated on the other sample of the same soil but under 0.2in. penetration. Moreover, one normal CBR test under continuous loading will be performed on the same soil in order to compare the results. To achieve our objective, we collected six clayey samples from different Lebanese zones. Proctor test was done first on each soil in order to find the optimum moisture content OMC which will be used to compact the soil for CBR test. The comparison of different tests performed on the same soil appears to be very fruitful. In fact, the loading - unloading - reloading cycle applied to clay tends to enhance the CBR values.
\end{abstract}

Keywords: Clay, California Bearing Ratio, cyclic load, loading-unloading-reloading

\section{Introduction}

The California bearing ratio (CBR) is a test to specify the mechanical strength of a soil. It is ratio between the actual pressure and the standard pressure under a constant penetration. It is usually done by a continuous load from the penetration piston. The soil tested should be under its optimum unit weight. For this reason, the proctor test is necessary to be done to find the optimum water content $(\mathrm{OMC})$ in order to compact the soil under its optimum unit weight. This kind of continuous load does not exist in real life. The traffic load on a highway is not uniform during the time. The motion of the traffic can be described as a cyclic load on the highway. For this reason, applying the cyclic instead of the continuous load on the CBR is necessary to find its impact on the soil and to simulate the traffic surcharge on the soil. Each load cycle is consisted from loading, unloading and reloading. The loading is made by switching on the machine, and then the unloading is reached after stopping piston penetration and turning the machine in reverse direction. The reloading is simply performed by applying again the load through the piston on the compacted soil. In many countries, especially Lebanon, the upper subgrade of many structures and highways is formed from clay. The clayey soils have a weak value of CBR especially when it is soaked because the water is trapped between its particles. In this case, the problem of the settlement starts to appear.

The cracks and the holes, that appear on the highways and cause many death accidents every year, are the main examples of this problem. The object of this project is to discover the influence of the cyclic load on the CBR of a soaked clay. To achieve this goal, many samples of clayey soil should be tested. In this purpose, six different samples of soils were collected from different Lebanese areas such as Jbaa, Houmin, Kfaromen, Shoukin, Kfartbnit and Zawtar. All these villages are located in Nabatiyeh region. Our objective is to try to find how the cyclic load can modify the CBR of clay. At the same time, we will try to find the effect of clay parameters on its behavior under cyclic load. These results were analyzed in a very accurate way to get a useful conclusion.

This project consists of two main parts:

- The experimental part: The proctor and the CBR tests are the main experiments that are related directly to this project. Moreover, the sieve analysis, specific gravity, Atterberg limits, hydrometer test and soil classification are important to identify and to recognize the clayey soil which is very important for result analysis. 
- The analysis part: in this part, the results of the previous experiments were collected together and analyzed to get the conclusions. These studies are made to find the effect of the cyclic load on the CBR of the clayey soils that are mentioned before.

During history, researchers have tried to solve this problem especially that in some country the use of clay as a subgrade is a must. In this purpose, they worked to enhance the CBR value of clayey soils by adding other materials to clay. Butt et al. [1] have used the human hair fibers to enhance the CBR of clayey soil. Frangieh et al. [2] tried to improve the CBR value of clay by draining the clay by using a layer of sand between the layers of clay in the CBR mold. Vibhakar and Nahta [3] used some fibers in the CBR mold to get higher CBR values. Wojcieh and Gluchowski [4] used a different type of load which is the cyclic load. They tried to discover its effects on the CBR of clay. Yetimoglu et al. [5] studied the effect of reinforcing sand fills with fibers overlying the soft clay.

\section{Experiments and Results}

All the soil experiments performed in this section are done, according to the American Society for Testing and Materials (ASTM) standards. In order to obtain consistent results, it is important to work on different samples of clayey soils to get credible and objective results. For this reasons, six samples of clayey soils were collected from six different locations in the south of Lebanon. The experiments which were performed on the soils are divided in two groups, the main experiments and the identification experiments:

- The main experiments are the Proctor test and the CBR test

- The identification tests are the Atterberg tests, the sieve analysis, the hydrometer test and the specific gravity.

\subsection{Proctor Test}

The first experiment is the Proctor test which is performed to find the optimum moisture content and the highest dry unit weight after the compaction of each soil. The molds used in this test have a height of $17 \mathrm{~cm}$, and a diameter of $15.2 \mathrm{~cm}$ according to the ASTM standards [6]. Five layers of soil were used in each mold.

\subsection{California Bearing Ratio Test}

For each soil, three molds should be compacted in the proctor machine under its OMC to perform the CBR test. Since this project is about the effect of the cyclic load on the CBR of a soaked clayey soil, these molds are put in the water for 4 days (96 hours) according the ASTM standards [7]. After 4 days, these molds are removed from water then drained for 15 minutes in a way to let the extra water goes out of the mold. First, the mold is placed on the machine and then steel rings of $4.54 \mathrm{Kg}$ are added to the mold. Finally, the test begun by turning on the machine.

Each mold is loaded in a different way than the other two molds:

The first mold is tested under a continuous load until the penetration reaches a value of 0.3 inches. The second mold is tested under a cyclic load at a 0.1 in penetration. This is done by loading, unloading and reloading the soil. The loading phase is when the piston is moving down through the soil. The unloading phase is when the machine is off and the piston moving up from the soil. The reloading is when the machine is switched on again and the piston is moving down the soil. These three phases form a cycle. Between the unloading phase and the reloading phase, a break of 10 min is needed for the soil to swell. This cycle is repeated four times, but in the last time the reloading stopped after a penetration of 0.3 in. The third mold is similar to the second one, concerning the way of loading, but what differs is that, in this mold, the penetration of 0.2 in is going to be studied. It means the cyclic load will be performed at $0.2 \mathrm{in}$. The results are given in figures below.

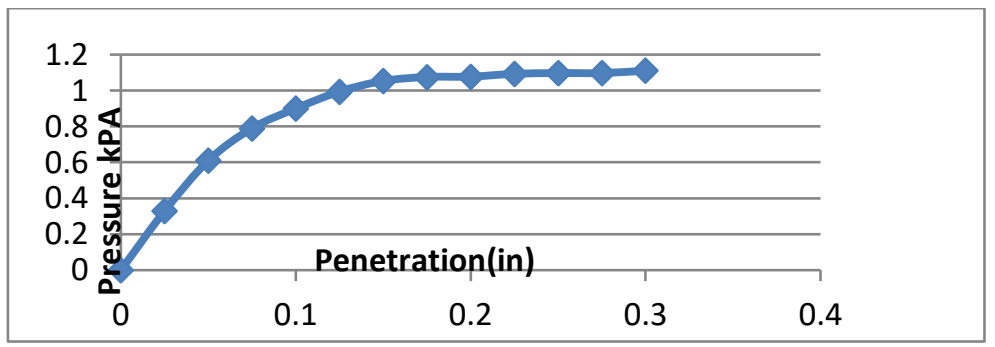

Fig. 1: CBR of soil sample 1 (Houmin) under continuous load. 


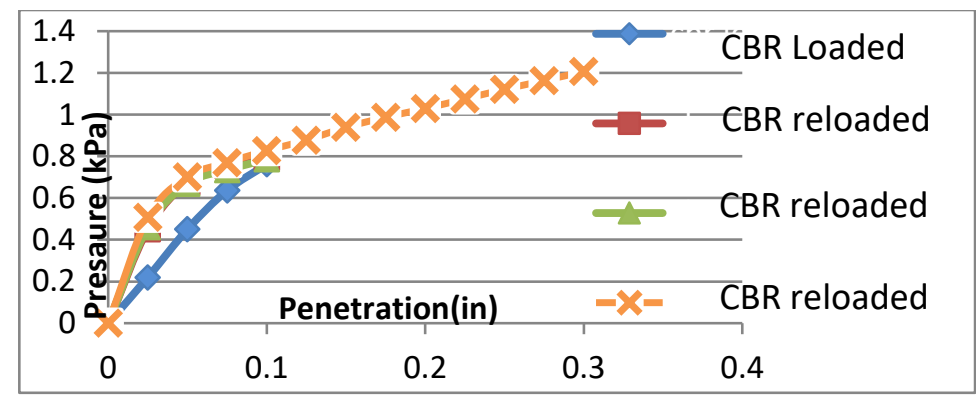

Fig. 2: CBR of soil sample 1 (Houmin) with wyclic load at 0.1 in penetration.

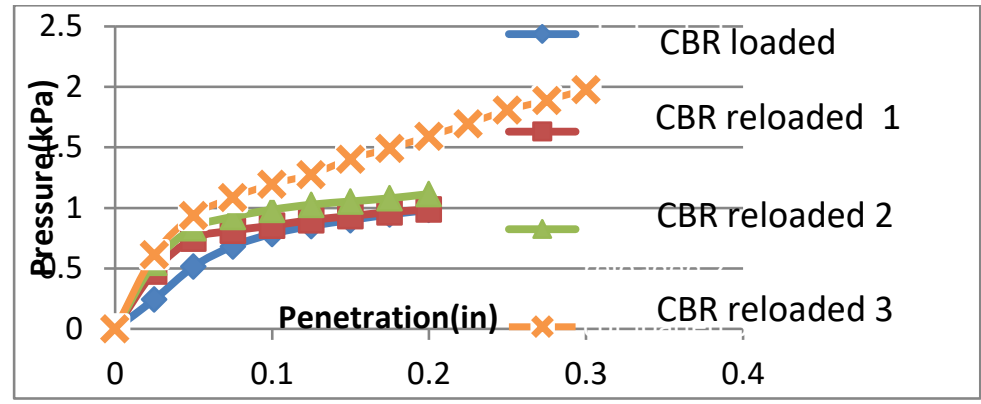

Fig. 3: CBR on soil sample1 (Houmin) with cyclic load at 0.2 in penetration.

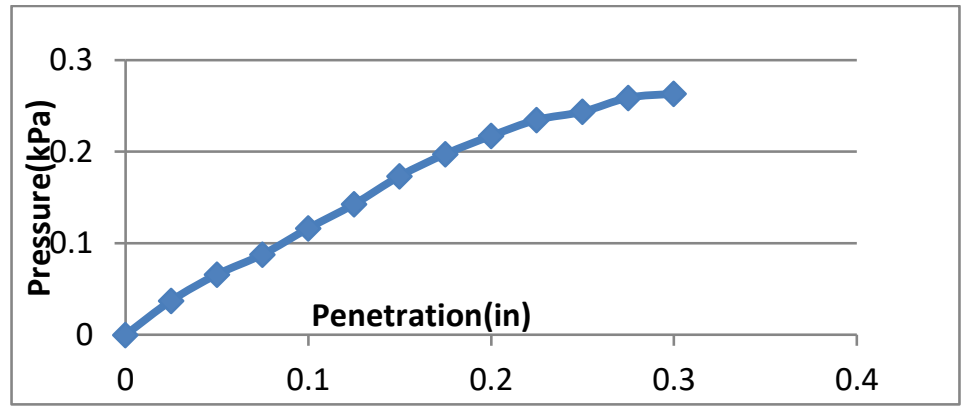

Fig. 4: CBR of soil sample 2 (Jbaa) under continuous load.

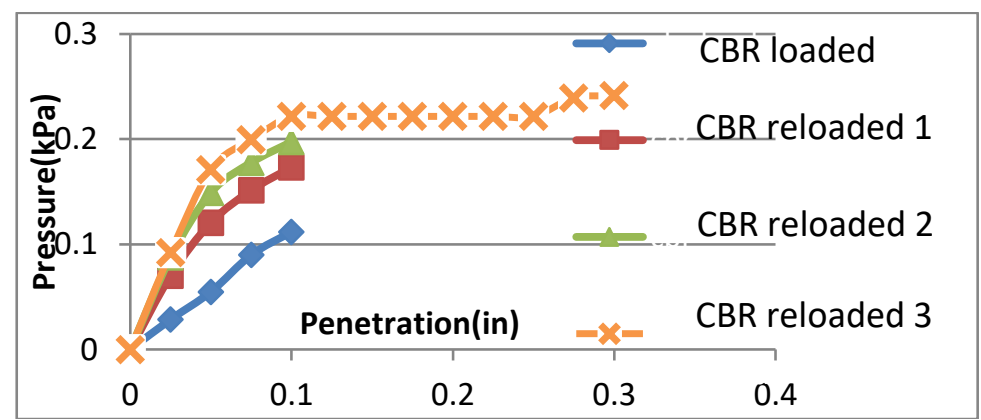

Fig. 5: CBR of soil sample 2 (Jbaa) with cyclic load at 0.1 in penetration. 


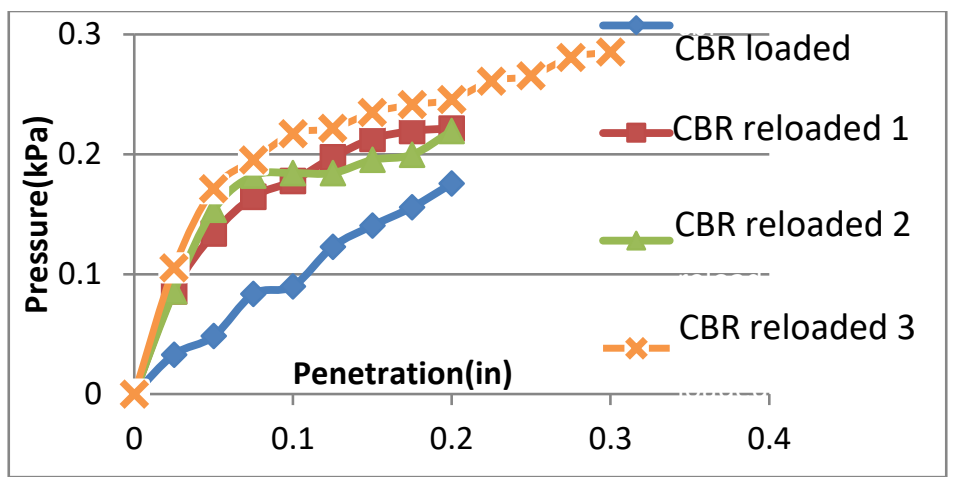

Fig. 6: CBR of soil sample 2 (Jbaa) with cyclic load at 0.2 in penetration.

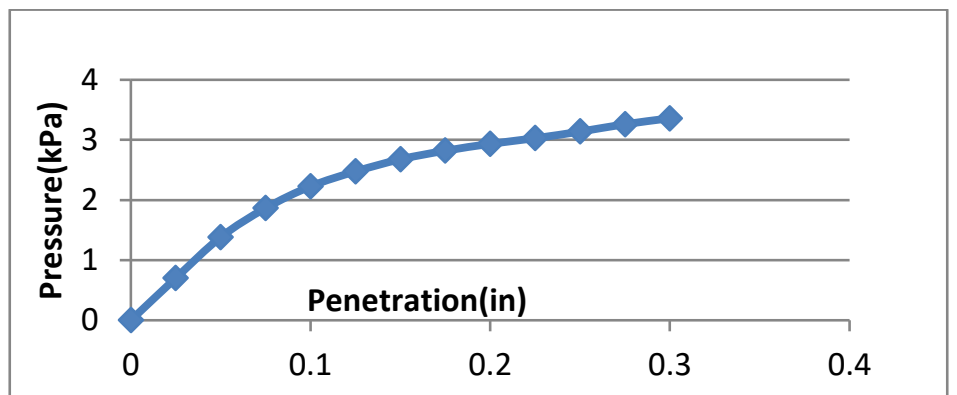

Fig. 7: CBR of soil sample 3 (Kfarroman) under Continuous Load.

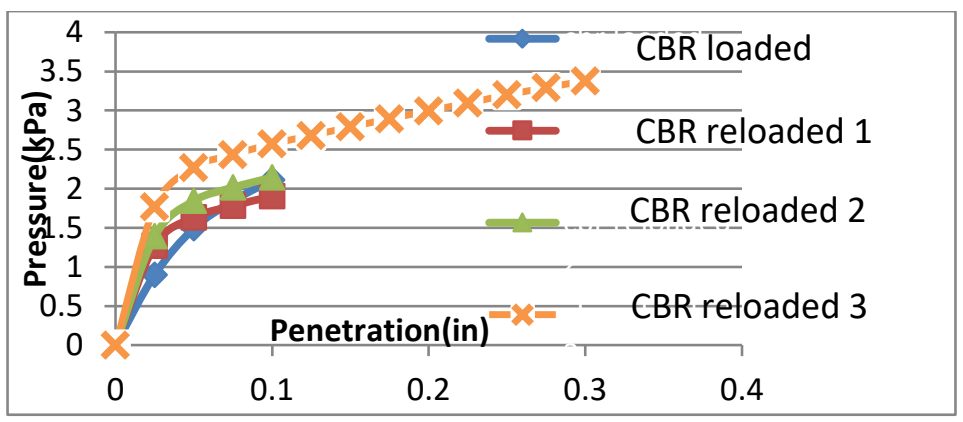

Fig. 8: CBR of soil sample 3 (Kfarroman) with cyclic load at 0.1 in penetration.

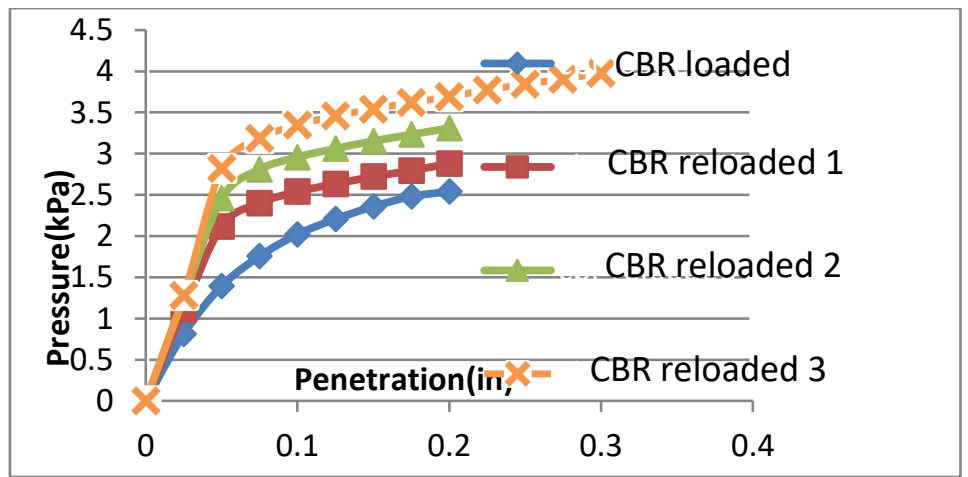

Fig. 9: CBR of soil sample 3 (Kfarroman) with cyclic load at 0.2 in penetration. 


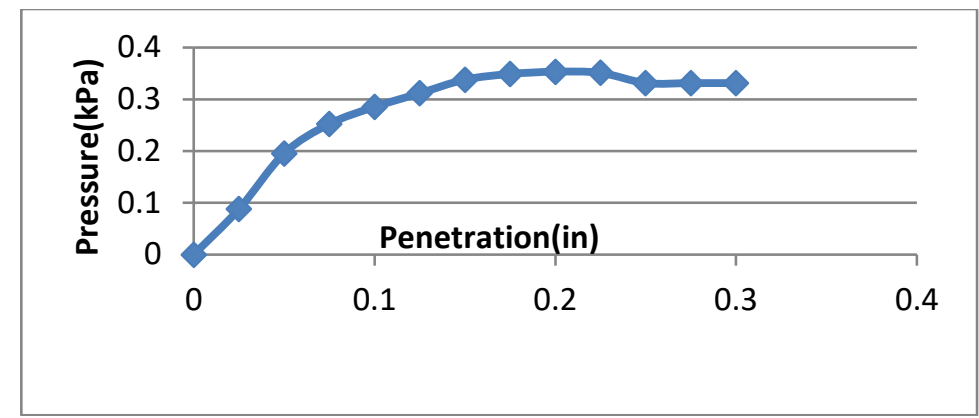

Fig. 10: CBR of soil sample 4 (Kfartbnit) under continuous load.

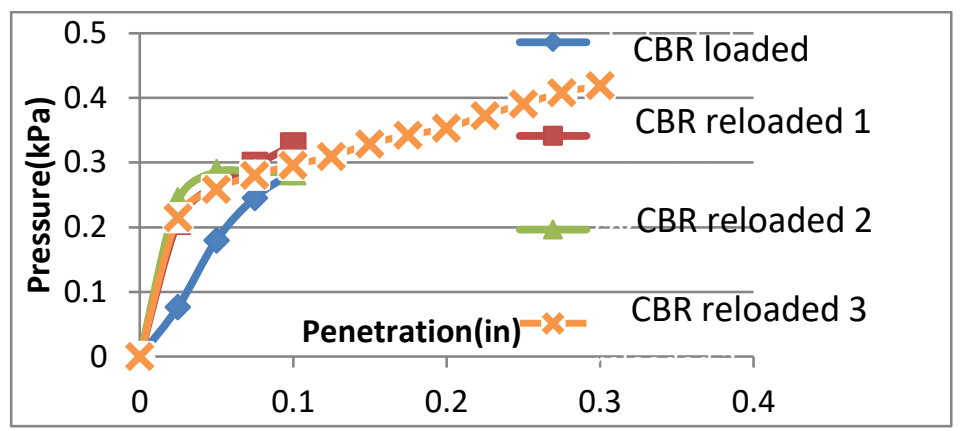

Fig. 11: CBR of soil sample 4 (Kfartbnit) with cyclic load at 0.1 in penetration.

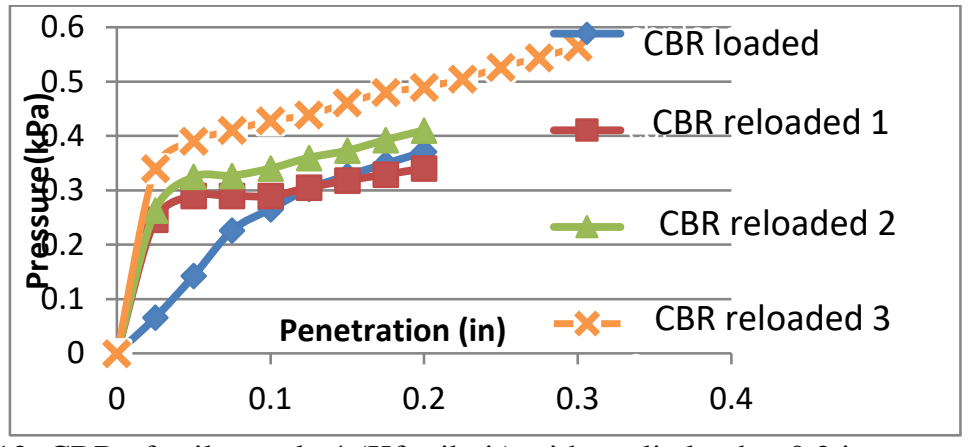

Fig. 12: CBR of soil sample 4 (Kfartibnit) with cyclic load at 0.2 in penetration.

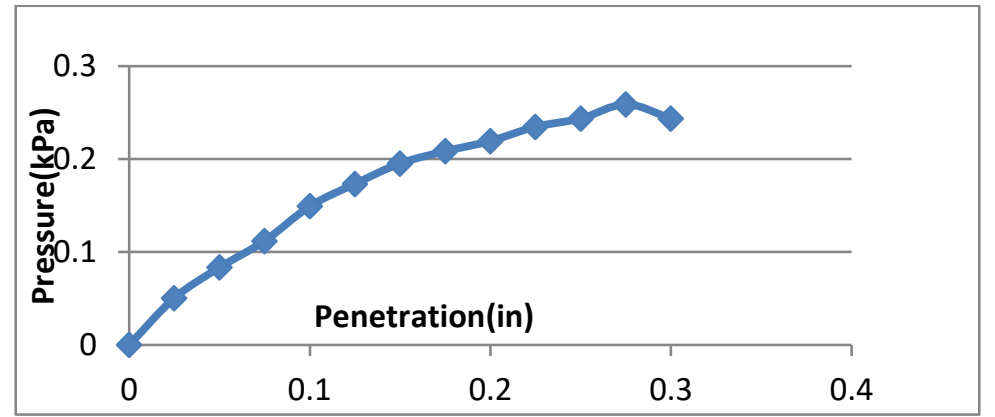

Fig. 13: CBR of soil sample 5 (Shoukin) under continuous load. 


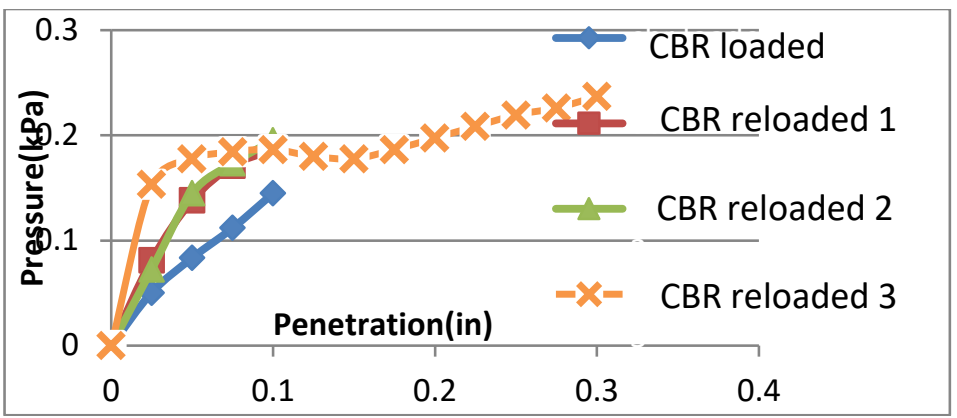

Fig. 14: CBR of soil sample 5 (Shoukin) with cyclic load at 0.1 in penetration.

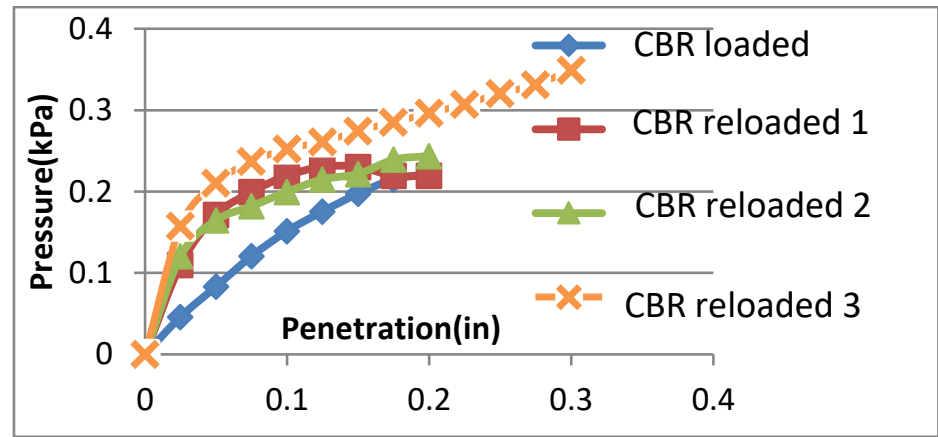

Fig. 15: CBR of soil Sample 5 (Shoukin) with Cyclic Load at 0.2 in Penetration.

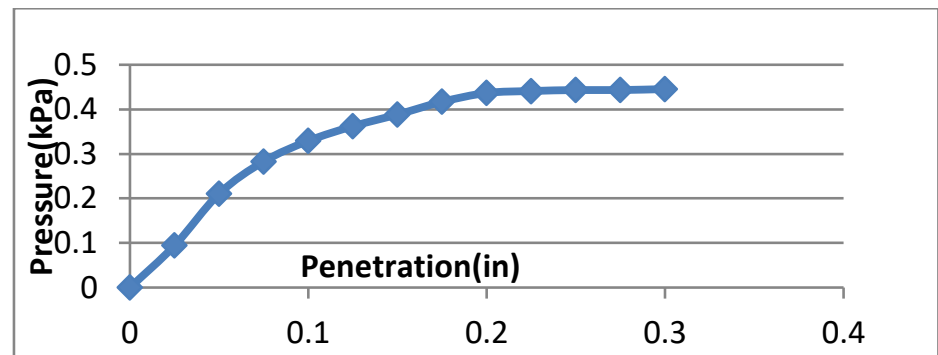

Fig. 16: CBR of soil sample 6 (Zawtar) under Continuous Load.

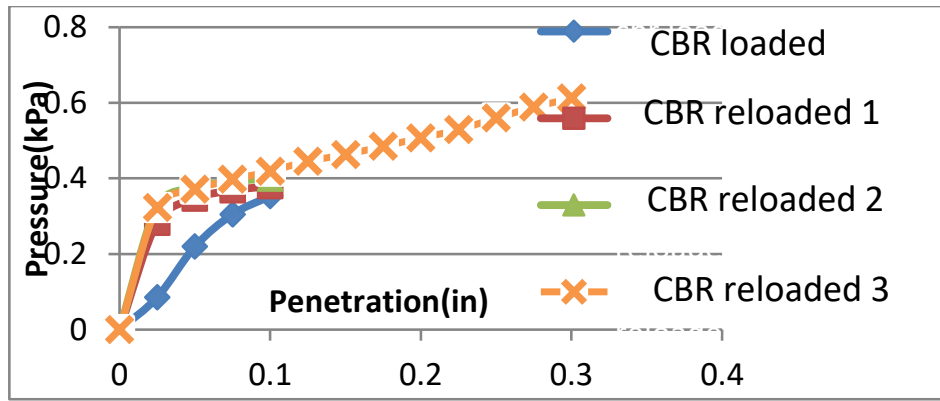

Fig. 17: CBR of soil sample 6 (Zawtar) with cyclic load at 0.1 in penetration. 


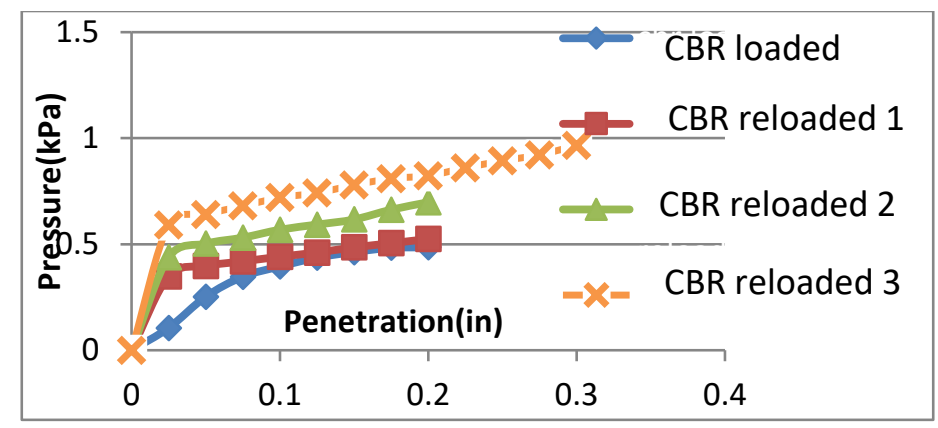

Fig. 18: CBR of soil sample 6 (Zawtar) with cyclic load at 0.2 in penetration.

\subsection{Identifications Tests}

After finishing the two previous tests, it is time to start the identification tests to be ready for the analysis part. Table 1 shows the results of all the tests including Atterberg limits [8], the sieve analysis [9], the specific gravity [10], the hydrometer test [11], the sand fraction, the silt fraction and the clay fraction.

Table 1. The identification tests results.

\begin{tabular}{|c|c|c|c|c|c|c|c|}
\hline Soils & $\begin{array}{c}\text { Plastic limit } \\
\text { PL \% }\end{array}$ & $\begin{array}{c}\text { Liquid Limit } \\
\text { LL \% }\end{array}$ & $\begin{array}{c}\text { Plasticity } \\
\text { Index PI \% }\end{array}$ & $\begin{array}{c}\text { Specific } \\
\text { Gravity G }\end{array}$ & $\begin{array}{c}\text { Sand } \\
\text { Fraction \% }\end{array}$ & $\begin{array}{c}\text { Silt fraction \% } \\
\text { Clay fraction } \\
\%\end{array}$ \\
\hline S1 & 44.82 & 60.76 & 15.94 & 2.55 & 14.14 & 19.07 & 31.28 \\
\hline S2 & 19.15 & 33.80 & 14.65 & 2.64 & 48.30 & 23.81 & 24.01 \\
\hline S3 & 33.33 & 52.74 & 19.41 & 2.73 & 9.56 & 26.52 & 62.01 \\
\hline S4 & 23.60 & 56.93 & 33.33 & 2.51 & 11.17 & 32.27 & 52.44 \\
\hline S5 & 43.85 & 57.94 & 14.09 & 2.54 & 6.94 & 23.00 & 53.99 \\
\hline S6 & 30.00 & 63.81 & 33.81 & 2.62 & 18.09 & 16.15 & 41.44 \\
\hline
\end{tabular}

\section{Analysis of Experimental Results}

After finishing all the experiments tests, we grouped the results of CBR tests performed on the six soils in table 2. In this table, there are four columns for each soil, CBR on virgin soil under continuous load, CBR on soil after one cyclic load, CBR on soil after two cyclic loads and CBR on soil after three cyclic loads. The first column shows the results of the CBR test performed on virgin soil for $0.1 \mathrm{in}$. and $0.2 \mathrm{in}$. penetration. The second, the third, and the fourth columns show the results of CBR and its increments ratio (Incr. ratio) for each cycle for $0.1 \mathrm{in}$. and $0.2 \mathrm{in}$. penetration. The increment ratio is how much the CBR has increased after each cycle.

Table 2: Summary of all the CBR tests performed on the soil samples.

\begin{tabular}{|l|l|l|l|l|l|l|l|l|l|l|l|l|l|l|l|}
\hline & \multicolumn{3}{|c|}{ CBR virgin } & \multicolumn{4}{|c|}{ CBR first cycle } & \multicolumn{3}{c|}{ CBR second cycle } & \multicolumn{3}{c|}{ CBR third cycle } \\
\hline Soils & 0.1 in. & $\begin{array}{l}0.2 \\
\text { in. }\end{array}$ & $\begin{array}{l}0.1 \\
\text { in. }\end{array}$ & $\begin{array}{l}\text { Incr. } \\
\text { ratio }\end{array}$ & $\begin{array}{l}0.2 \\
\text { in. }\end{array}$ & $\begin{array}{l}\text { Incr. } \\
\text { ratio }\end{array}$ & 0.1 in. & $\begin{array}{l}\text { Incr. } \\
\text { ratio } \\
\text { in. }\end{array}$ & $\begin{array}{l}\text { Incr. } \\
\text { ratio }\end{array}$ & 0.1 in. & $\begin{array}{l}\text { Incr. } \\
\text { ratio }\end{array}$ & $\begin{array}{l}0.2 \\
\text { in. }\end{array}$ & $\begin{array}{l}\text { Incr. } \\
\text { ratio }\end{array}$ \\
\hline S1 & 0.90 & 1.08 & 0.80 & 0.89 & 0.99 & 0.92 & 0.79 & 0.87 & 1.11 & 1.03 & 0.83 & 0.92 & 1.59 & 1.48 \\
\hline S2 & 2.23 & 2.93 & 1.90 & 0.85 & 2.88 & 0.98 & 2.14 & 0.96 & 3.31 & 1.13 & 2.57 & 1.15 & 3.69 & 1.26 \\
\hline S3 & 0.29 & 0.35 & 0.33 & 1.15 & 0.34 & 0.96 & 0.29 & 1.00 & 0.41 & 1.16 & 0.30 & 1.04 & 0.49 & 1.39 \\
\hline S4 & 0.15 & 0.22 & 0.19 & 1.25 & 0.22 & 1.00 & 0.20 & 1.31 & 0.24 & 1.11 & 0.19 & 1.25 & 0.30 & 1.35 \\
\hline S5 & 0.33 & 0.44 & 0.38 & 1.15 & 0.52 & 1.20 & 0.40 & 1.21 & 0.70 & 1.60 & 0.42 & 1.27 & 0.82 & 1.88 \\
\hline S6 & 0.12 & 0.22 & 0.17 & 1.49 & 0.22 & 1.02 & 0.20 & 1.70 & 0.22 & 1.01 & 0.22 & 1.91 & 0.25 & 1.13 \\
\hline
\end{tabular}

After analyzing the tests results in the above table, we made the following conclusions:

The soil S5 which has the lowest sand fraction equal to 6.94\% presents the highest CBR increment ratio at 0.2 in. under all cyclic loads. Under 0.1 in penetration, this soil does not show a high CBR increment like other soils because of his weak drainage capacity. The low sand fraction gives a weak drainage capacity for the soil. For this reason, it needs 
more pressure and more time to lose its water. This demonstrates why under 0.2 in. the CBR increment increases and not under $0.1 \mathrm{in}$. Under 0.2 in penetration, the water is pushed out so the increment ratio becomes the highest, compared to the other soils which have started to lose water earlier.

The soil S2 with the highest sand fraction which is equal to $48.29 \%$ and the smallest clay fraction which is equal to $24.01 \%$ have shown the highest CBR on virgin soil. This is logical since the granular soil is subjected to soil densification during CBR test. On the other hand, this soil has a modest CBR increment under cyclic load. This is explained by the fact that the soil matrix of the granular soil will not be affected by cyclic loads.

The increment ratio of CBR varies between 0.85 and 1.49 for the first cycle and between 0.87 and 1.60 for the second cycle and between 0.92 and 1.91 for the third cycle. This demonstrates that if more load cycles are done, the increment of CBR will increase and the soil will be stronger. More cycles mean that the soil will be further confined. After trying to find a relation between the clay fraction and the results of CBR after each cycle, it seems that the clay fraction alone cannot play any role affecting the CBR increment because the soil with minimum and maximum clay fraction has intermediate CBR values.

\section{Conclusion}

After analyzing all the results, and getting the previous remarks, it is very clear to conclude that the cyclic load is beneficial for a clayey subgrade. In fact, after we performed all the needed tests for this project, we found that the CBR value of the clay have increased at $0.1 \mathrm{in}$. and $0.2 \mathrm{in}$. penetration almost after each cyclic load. The most important conclusion is that if more cycles are done on the clayey samples, higher will be the final CBR values.

\section{References}

[1] W. A. Butt, B. A. Mir and J. N. Jha, "Strength behaviour of Clayey Soil Reinforced with Human Hair as Natural Fiber," International Journal of Geotechnical and Geological Engineering, vol. 34, no.1, pp. 411-417, 2016.

[2] G. Abdallah, S. Ghaleb Frangieh and G. Mokel,"'Effect of Interbedded Sandy layer on CBR of Clayey Soil: A preliminary study," M.S. final project, Dept. Civil Eng., University of Balamand, Lebanon.

[3] N. Vibhakar and S. Nahta, "Study of the effect of coir fiber reinforcement on the strength parameters and CBR value of clayey soil," International Journal of Engineering Research \& Technology, vol. 3, no. 4, pp. 471-479, 2014.

[4] S. Wojcieh and A. Gluchowski, "Application of cyclic CBR test to approximation of subgrade displacement in road pavement," Architectura, vol. 12, no. 1, pp. 51-61, 2013.

[5] T. Yetimoglu, M. Inanir and O. E. Inanir, "A study on bearing capacity of randomly distributed fiber reinforced sand fills overlying soft clay," Elsevier Geotextiles and Geomembranes, vol. 23, no. 2, pp. 174-183, 2004.

[6] ASTM Standard D698, "Standard Test Methods for Laboratory Compaction Characteristics of Soil Using Standard Effort," in ASTM International, pp. 78-88, 2001.

[7] ASTM Standard D1883, "Standard Test Methods for CBR of Laboratory-Compacted Soils," in ASTM International, pp. 170-177, 2001.

[8] ASTM Standard D4318, "Standard Test Methods for Liquid Limit, Plastic Limit and Plasticity Index of Soils," in ASTM International, pp. 561-574, 2001.

[9] ASTM Standard D422, "Standard Test Methods for Particle-Size Analysis of Soils," in ASTM International, pp. 10$17,2001$.

[10] ASTM Standard D854,"Standard Test Methods for Specific Gravity of Soil Solids by Water Pycnometer," in ASTM International, pp. 93-99, 2001.

[11] ASTM Standard D1140,"Standard Test Methods for Amount of Material in Soils Finer Than the No. 200 Sieve" in ASTM International, pp. 100-103, 2001. 